\title{
Posterior fossa dural arteriovenous fistula
}

\author{
Adam A. Dmytriw MD MSc, Abdullah Alrashed MD, Victor X.D. Yang MD PhD
}

— Cite as: CMAJ 2020 March 2;192:E207. doi: 10.1503/cmaj.190920

A 61-year-old man with a decade-long history of a pulsatile bruit in his right ear presented to our institution for workup by ambulance after a seizure. He had received treatment previously for Ménière disease without improvement. The patient reported that the bruit had disappeared 2 months before presentation.

Diagnostic cerebral angiography showed that the patient had a large-Borden II dural arteriovenous fistula with 5 arteriovenous anastomoses, throughout the right transverse sinus, right torcula herophili, left sigmoid sinus/jugular bulb and superior sagittal sinus (Figure $1 \mathrm{~A}$ and $\mathrm{B}$ ). Because of the risk of hemorrhage, he underwent embolization of the entire posterior venous sinus system with platinum coils and liquid adhesive (Figure $1 \mathrm{C}$ and D; Appendix 1, Supplementary Figure 1, available at www.cmaj.ca/lookup/suppl/doi: 10.1503/cmaj.190920/-/DC1). The risk of venous infarct was considerable, and he was monitored carefully.

After 3 weeks in a low level of consciousness, our patient made a full recovery. Two years later, he reported a recurrence of rightsided tinnitus that was pulsatile but different in quality to his original bruit. A repeat cerebral angiography showed that he had a small new Borden I dural arteriovenous fistula (Appendix 2, Supplementary Figure 2A and B, available at www.cmaj.ca/lookup/ suppl/doi:10.1503/cmaj.190920/-/DC1), which is being observed. His compensatory collateral network had also grown (Appendix 2, Supplementary Figure 2C and D).

Dural arteriovenous fistulae are predominantly acquired anastomoses between intracranial veins and dural arteries, usually related to trauma or cerebral venous thrombosis. ${ }^{1,2}$ Our patient had sustained trauma during construction work a decade earlier, and a combination of trauma and subsequent thrombosis were likely synergistic given the size of the lesion.

Crude detection rates for dural arteriovenous fistulae have been reported at $0.29-0.51$ per 100000 , with less than $8 \%$ of these having multiple fistulae. ${ }^{3} \mathrm{~A}$ retrospective review involving 220 patients with dural arteriovenous fistulae in South Korea reported that $13.6 \%$ of patients presented with pulsatile tinnitus as their only initial symptom, ${ }^{4}$ whereas another retrospective review involving 69 patients in Taiwan found that $82 \%$ of patients with large sinus fistulae had pulsatile tinnitus. ${ }^{5}$

This case underlines that change, or even disappearance of symptoms associated with a dural arteriovenous fistula, merits angiography.
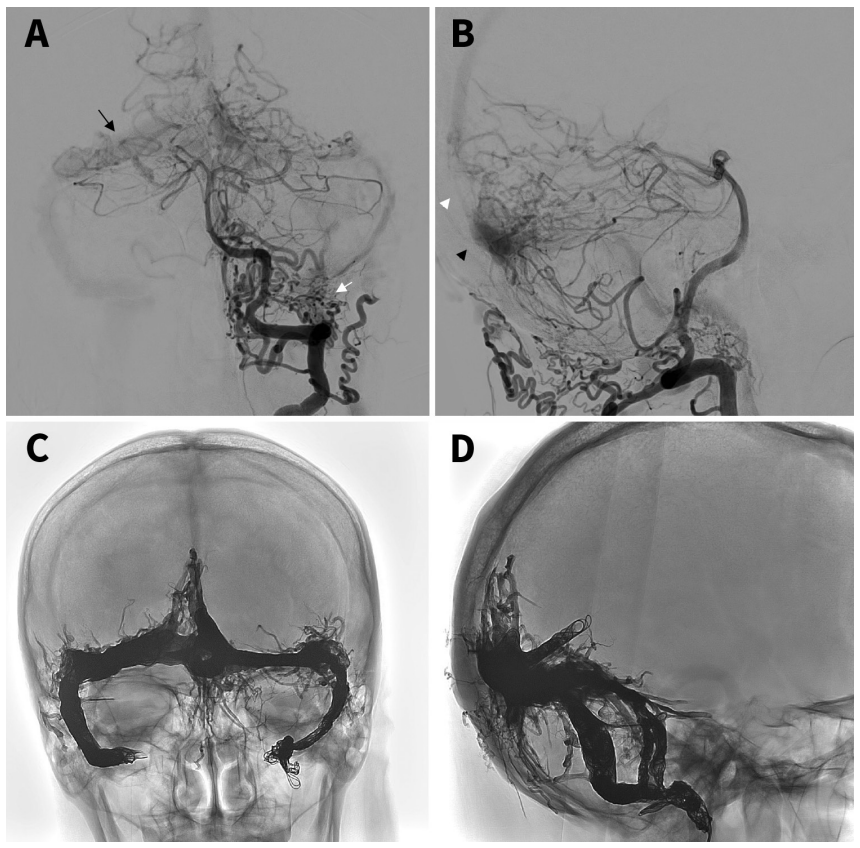

Figure 1: Intraoperative catheter angiography for dural arteriovenous fistula involving all of the major dural venous sinuses in a 61-year-old man with a decade-long history of pulsatile bruit in his right ear. (A) Anteroposterior and (B) lateral angiograms of a large dural arteriovenous fistula with 5 venous anastomoses at the right transverse sinus (black arrow), right torcula herophili (black arrowhead), left sigmoid sinus/jugular bulb (white arrow) and superior sagittal sinus (white arrowhead). Postoperative fluoroscopy showing reduction in shunting with transvenous coiling and liquid adhesive embolization, with (C) unsubtracted anteroposterior and (D) lateral fluoroscopy showing endovenous coils and liquid adhesive within the proximal superior sagittal sinus and torcula herophili, as well as the bilateral transverse and sigmoid sinuses and jugular bulbs.

\section{References}

1. Miller TR, Gandhi D. Intracranial dural arteriovenous fistulae: clinical presentation and management strategies Stroke 2015;46:2017-25.

2. Abud TG, Nguyen A, Saint-Maurice JP, et al. The use of onyx in different types of intracranial dural arteriovenous fistula. AJNR Am J Neuroradiol 2011;32:2185-91.

3. Hiramatsu M, Sugiu K, Hishikawa T, et al. Epidemiology of dural arteriovenous fistula in Japan: analysis of Japanese Registry of Neuroendovascular Therapy (JR-NET2). Neurol Med Chir (Tokyo) 2014;54(Suppl 2)63-71.

4. An Y-H, Han S, Lee M, et al. Dural arteriovenous fistula masquerading as pulsatile tinnitus: radiologic assessment and clinical implications. Sci Rep 2016;6:36601.

5. Tsai LK, Jeng JS, Liu HM, et al. Intracranial dural arteriovenous fistulas with or without cerebral sinus thrombosis: analysis of 69 patients. J Neurol Neurosurg Psychiatry 2004;75:1639-41.
Competing interests: None declared.

This article has been peer reviewed.
The authors have obtained patient consent.

Affiliation: Sunnybrook Health Sciences Centre, Neurovascular Service, Toronto, Ont.
Correspondence to: Victor Yang, victor. yang@sunnybrook.ca 